\title{
Biomass Analysis by Means of Environmental Economics
}

\author{
Stephanos D. V. Giakoumatos, Odysseas N. Kopsidas \\ School of Maritime and Industrial Studies, University of Piraeus, Piraeus, Greece \\ Email: sgiakou@hotmail.com, sgiakoum@webmail.unipi.gr, odykopsi@yahoo.gr
}

How to cite this paper: Giakoumatos, S. D. V., \& Kopsidas, O. N. (2021) Biomass Analysis by Means of Environmental Economics. Low Carbon Economy, 12, 22-41. https://doi.org/10.4236/lce.2021.121002

Received: February 2, 2021

Accepted: March 28, 2021

Published: March 31, 2021

Copyright (C) 2021 by author(s) and Scientific Research Publishing Inc. This work is licensed under the Creative Commons Attribution International License (CC BY 4.0).

http://creativecommons.org/licenses/by/4.0/

\begin{abstract}
The latest years, oil and gas demand reduction incurred market turbulences as a result of oil wells exploitation uncertainties and new green policies towards sustainability that turn the stakeholders to eco-friendlier energy sources. A challenging alternative to this direction is the increment of biomass share in the overall consumed energy balance. From many standpoints of view, biomass has minor impact on the $\mathrm{CO}_{2}$-cycle balance "operating" as an offset against $\mathrm{CO}_{2}$ photosynthesis. In the present work, a practically holistic interpretation of biomass energy contribution in our societies was outlined. Expert systems were developed as a tool to biomass energy analysis and certain models were presented to approach estimation of individual parts of biomass exploitation chain. The tendency of energy crop land availability and best cultivated practices were presented as well. A schematic cost analysis of biomass utilization was performed under most common operational scenarios. Economic evaluation, future strategic planning and environmental impact from energy biomass utilization were all analyzed up to a certain point. Biomass as a renewable energy form is expected to bring about a positive cost/benefit ratio. Biomass, in general, is easier to handle, (storage-transportation), cost-effective and more beneficial in terms of greenhouse gases (GHG) net emissions as results from an incorporated ad hoc developed SWOT analysis.
\end{abstract}

\section{Keywords}

Biomass, Economics, Cost, Benefit, Greenhouse Gases, Sustainability, SWAT Analysis

\section{Introduction}

Undoubtedly nowadays, energy consumption is increasing continuously due to advanced industrialization and population growth. Basic fossil derived energy 
sources up to our days were mainly crude oil and natural gas. The basic well established energy sources are hydro, nuclear, solar, wind, sea waves, fossil fuels i.e. crude oil, natural gas \& coal (Kulkarni \& Dalai, 2006). Petroleum as a fossil fuel, crude oil derivative, holds globally a considerable market share. All petroleum by-products incur severe atmospheric pollution mainly by the extensive use of diesel fuel oil and contribute to greenhouse gas (GHG) increase. Apart from GHGs, diesel fuel oil consumption also contributes to other air pollutants including $\mathrm{NO}_{\mathrm{x}}, \mathrm{SO}_{\mathrm{x}}, \mathrm{CO}$, particulate matters (PMs) and volatile organic compounds (VOCs) (Klass, 1998).

Furthermore, oil market experts are worried about periodic oil price shocks which lead to huge cost to all oil production and transport stages. It is estimated an overall $\$ 233$ billion per annum burden, over the past 45 years up to 2000, due to oil drill/refinery/storage and transport (Greene \& Tishchishyna, 2000). Diesel engines are widely considered to be unsustainable on account of oil wells gradual depletion (Sharif, Aishah, \& Boyce, 2008). The transition to the new energy forms (as the renewable) is getting more and more urgent due to the threat of global climate change caused largely by the burning of fossil fuels (Hall \& Scrase Will, 1998). The contribution of fossil fuels to the carbon dioxide level increment and the association to the global warming of the planet, contribute to certain negative phenomena i.e. acidic deposition, groundwater contamination, and human health effects (Hubbard, 1991; Sharif, Nasrulhaq, Majid, Chandran, \& Zuliana, 2007). The environmental cost as a result of the fossil fuel use should be discriminated clearly between the social and variable cost of the entrepreneur. As a result, researchers have highlighted the need to reconsider more sustainable, eco-friendly and less expensive energy sources (Sharif, Nasrulhaq, Majid, Chandran, \& Zuliana, 2007; McLaughlin, Samson, Bransby, \& Wiselogel, 1996).

Kyoto agreement in December of 1997 inaugurated a global turning point policy in terms of the necessity of carbon dioxide $\left(\mathrm{CO}_{2}\right)$ and other greenhouse gas (GHG) reduction at least 5\% below given 1990 (GHG) levels as a base line, before 2012. However, large-scale introduction of biomass derived energy could contribute to sustainable development on several fronts, environmentally, socially and financially (McLaughlin, Samson, Bransby, \& Wiselogel, 1996) up to the point to claim that scientists' support that biomass is considered to be one of the best sources of energy (Kulkarni \& Dalai, 2006) and a way to mitigate greenhouse gas emissions (Turkenburg, 2000).

Bioenergy and bio-based products are approaching near-zero net emissions of greenhouse gases (GHG) and thereof renewable energy, carbon neutral in transport fuels are vital for environmental and economic sustainability. Biomass has potentially a minor impact on the atmospheric $\mathrm{CO}_{2}$ overall emissions functioning as an offset against $\mathrm{CO}_{2}$ produced by photosynthesis (Hall, Rosillo-Calle, Williams, \& Woods, 1993; Macedo, 1998). Biomass improves soil and water quality and increases net economic returns to a depressed rural economy (McLaughlin, Samson, Bransby, \& Wiselogel, 1996) resulting in significant eco- 
nomic and environmental benefits to the society and a great leap towards sustainability (Sharif, Nasrulhaq, Majid, Chandran, \& Zuliana, 2007) and to the climate stabilization (Hall, Rosillo-Calle, Williams, \& Woods, 1993).

\section{Biomass for Energy Production}

\subsection{Biomass in Energy Statistics and Models}

Numerous researchers are studied extensively feasibility and energy potential of various biomass resources and paved the way for integrative projections of future biomass resource availability (LaTourrette, Ortiz, Hlavka, Burger, \& Cecchine, 2011). Biomass energy flow charts ease the actual assessment in terms of biomass quantification and use. In flow charts developed for Kenya and Zimbabwe (Hall, Rosillo-Calle, Williams, \& Woods, 1993), it is estimated that barely $45 \%$ of the available biomass reaches end users, due to losses, inefficient conversion and underuse. Statistics published by Food \& Agricultural Organization (FAO), underestimate greatly the available resources. By using flow chart approaches it is easier to pinpoint bioenergy sector mechanisms towards future expansion and best available management for climate change mitigation (Hall, Rosillo-Calle, Williams, \& Woods, 1993).

The same principles more or less apply in industrialized countries where domestic state energy policies are often poorly informed as regards biomass resources and potentials. Should local data is available on biomass potential, macroscale estimates of national based potentials can be made by means of tool development for analyzing options and strategies in the bioenergy sector (Hall, Rosillo-Calle, Williams, \& Woods, 1993). For example, BEFAT (Biomass Energy Flow Analysis Tool) is an expert system for the integration of data on local, regional and national scales in the UK (Macedo, 1998).

According to reviewers (LaTourrette, Ortiz, Hlavka, Burger, \& Cecchine, 2011), Oak Ridge National Laboratory estimated that the U.S. biomass resource from agricultural lands ranges from approximately 190 million dry tons (3.2 billion giga joules [GJ]) to almost 1 billion tons (17 billion GJ) providing that field yields improve significantly and cropland which currently is used for food crops in future terms is dedicated to produce biomass for energy. 190 million dry tons of biomass could generate about 300 terawatt-hours of electricity, approximately $8 \%$ of 2008 U.S. consumption (Energy Information Administration [EIA], 2010) given that U.S. coal production in 2008 was approximately 25 billion GJ. Also, a National Academy of Sciences panel estimated that agricultural lands can currently produce 220 million tons ( 3.7 billion GJ) of biomass and could produce up to 320 million tons (5.4 billion GJ) of biomass by 2020 (LaTourrette, Ortiz, Hlavka, Burger, \& Cecchine, 2011).

\subsection{Modeling Biomass Energy Supply from Agricultural Lands}

Energy demand growth boosts biomass use in developing countries where alter- 
native sources are often unavailable (LaTourrette, Ortiz, Hlavka, Burger, \& Cecchine, 2011) determines three prerequisite stages to achieve biomass supply from agricultural land for energy production i.e., 1) biomass production land allocation, 2) biomass crops growing and harvesting, 3) harvested crops transport \& storage before consumed in a power plant and (Van Dama, Faaija, Lewandowskia, \& Fischerb, 2007) presented a biomass certification system.

According to (Faaij, Wagener, Junginger, van Weereld, Schouwenberg, Kwant et al., 2006) cost analysis study for biomass energy, the total average cost in Brazil and Ukraine, is estimated to be at about (1 Euro/2.5 GJ) directly competitive to gas and oil and is calculated as given below:

$$
C=\frac{\sum_{i=1}^{i_{t}}\left(\operatorname{ecc}_{i} \sum_{y=1}^{n} \frac{f_{i}(y)}{(1+d r)^{y}}\right)}{y l d \operatorname{rot} \sum_{y=1}^{n} \frac{f_{y l d}(y)}{(1+d r)^{y}}}
$$

where:

$\left(i_{t}\right) 1 / 4$ number of cost items with different time pattern, (dimensionless);

(C) $1 / 4$ cost of biomass (Volume per dry tonne);

(yld) $1 / 4$ yield of the energy crop, based on rain-fed production, [oven dry tonne per hectare per year];

(rot) $1 / 4$ rotation cycle (year);

(n) $1 / 4$ number of years of plantation lifetime (year);

$\left(e c c_{i}\right) 1 / 4$ cost of energy crop cost item (V);

$f_{i}(y) \quad 1 / 4$ number of times that cost item $(i)$ is applied on the plantation in year $(y)$ (dimensionless);

(dr) 1/4 discount rate (dimensionless);

$f_{\text {yld }}(y) \quad 1 / 4$ binary number, harvest (1) or not (0) in year $y$ (dimensionless).

The cost of supplying biomass energy to a power plant is therefore expressed by the general relationship:

$$
\begin{aligned}
\text { Cost of biomass }= & \text { land cost }+ \text { crop production cost } \\
& + \text { transportation cost }+ \text { storage cost }
\end{aligned}
$$

A cultivated plot of land yield specific biomass tonnage per square meter/area unit, given certain productivity parameters to affect the crop yield/biomass cost and market supply cost.

La Tourrette et al. (LaTourrette, Ortiz, Hlavka, Burger, \& Cecchine, 2011), demonstrated biomass cost estimation under several scenarios with different land fertility/crop variety/powerplant vicinity before burning to produce energy. They included transportation cost given as (costs per mass unit per distance) i.e. dollars per ton-mile. An important cost element is the intermediate storage (e.g. incorporating building, operating cost of the storage barn) and loading and unloading cost before and after dispatch (supply chain). 


\subsection{Agricultural Crops for Biomass Energy}

Agricultural energy crops are cultivated merely for energy production. As such, there is a great variety of stems to be utilized. For example, some crops resemble wood in their fiber structure (SRC) and can be used for energy production some others could be grass-like (miscanthus) or even rape, maize even some grasses (LaTourrette, Ortiz, Hlavka, Burger, \& Cecchine, 2011). Their residual part (straw) is consumed to produce heat and power generation. Energy crops are also used for biofuels and biogas production.

Studies in the past (An \& Searcy, 2012) demonstrated that there could be a potential significant cost reduction in energy crop cultivation, regarding especially the use of the establishments and harvest phases. Fertilization might be another important field for further improvement. It is estimated that the establishment cost climbs up to 15 percent of the total cost. Nevertheless, a sharp cost reduction could be achieved up to $30 \%$ along with the harvest cost reduction (up to $20 \%$ of the total cost), as a result of the ongoing equipment improvement. Greater plots of land dedicated exclusively to energy crop cultivation incur a transportation cost haircut more efficient corps exploitation and better infra structure utilization (i.e. specialized harvesters than the general farming practices that are used today). Fertilization cost rises between (10\% to $15 \%)$ of the total cost though it could be dropped employing an elevated spreader instead of custom-made solutions.

Energy crops secure income every three to five years. It takes at least two harvest cycles to recoup the initial investment. Corn stover collection and switch grass cultivation are considered to be the most sensitive to uncertainties. La Tourrette et al. (LaTourrette, Ortiz, Hlavka, Burger, \& Cecchine, 2011) presented mechanisms to switch from one cultivation (corn stover) to another (switch grass) and control in a better way the operational cost. Land and crop selection is greatly susceptible to official political reformations governing GHG emissions i.e. carbon dioxide emission credits. A low-cost biomass mixture comprises of corn stover, switch-grass grown in cropland pasture and switch-grass cultivated in cropland. Any emission policy change incurs simultaneously uncertainty and intangible operational cost. The degree of the impact might be varied from one location to another. Still carbon pricing tendency leans towards croplands and therefore energy crops are expected to compete plots of land used for food crops up to our days. This inclination is going to incur gradual food crop production decrease and as a consequence a food crop price increment. A great danger is lurking if this is the case. A possible deforestation is to take place so as food crops maintain the prior productivity. The lifecycle GHG emissions do not account for emissions from such indirect land-use changes (Van Dama, Faaija, Lewandowskia, \& Fischerb, 2007).

If calculations of GHG emissions associated with switch grass production engage both local carbon retention and indirect carbon emissions from deforestation, the cost advantage of growing switch-grass in croplands is diminishing and 
might favor energy crop production on degraded lands, which would have no effect on food production (LaTourrette, Ortiz, Hlavka, Burger, \& Cecchine, 2011).

\subsection{Agricultural Lands Available for Producing Biomass Energy}

When producing biomass energy displaces some other land use, the forgone profit from the displaced land use must be counted as part of the cost of producing biomass energy resources. Areas of each land type in each county are used to calculate the biomass energy available in each supply unit. Producing switch-grass displaces some other use of the land-food crops on cropland, grazing on cropland pasture, or the conservation value of CRP land. The forgone profit from these activities is approximated by the land rental rates (LaTourrette, Ortiz, Hlavka, Burger, \& Cecchine, 2011).

The relative value of a cultivated plot of land is a function of the soil depth and nutrient quality, local climate, irrigation techniques and other factors. Rental plots are in general higher for cropland, followed by CRP land (80 - 90 percent of cropland rent) and the lowest rent prices are for pastureland (approximately 25 percent of the cropland rent). Although there is substantial variability among individual countries, this generalized prizing approach, in fact, reflects the average relative productivity of different land types. CRP land is typically retired marginal quality cropland. Pastureland is inappropriate for the most crops aimed at food production.

Decoding the following EU report "Atlas of biomass potentials" (McLaughlin, Samson, Bransby, \& Wiselogel, 1996), a comparison was drawn for the cost of 5 archetypic biomass value chains, with a projection to the cost levels in 2020, considering that value chains were to be scaled up. Four out of the five value chains had a cost improvement potential ranging from $15 \%$ to $20 \%$. However, one of the presented chains (local agricultural residues for CHP plants), achieved an improvement potential that were leveling up to 40 percent. There were significant cost improvement opportunities in all steps of the value chain.

Cost improvement potential in a technology though is taken for granted as "mature" is perhaps surprising. The explanatory argument behind this is that several steps of the value chain were in fact in small scale and relatively immature at that period. For example, forest residues were exploited to a significant level in Scandinavia and agricultural residues exploited to a significant extent in Denmark.

\subsection{Production Cost}

The technology engaged to deploy biomass is translated into economic potential by estimating the production cost based on the level of technology and the selected agricultural production system applied to produce the bioenergy (Van Dama, Faaija, Lewandowskia, \& Fischerb, 2007). As the following Figure 1 shows, the production cost is divided into two different variables. The fixed cost, 


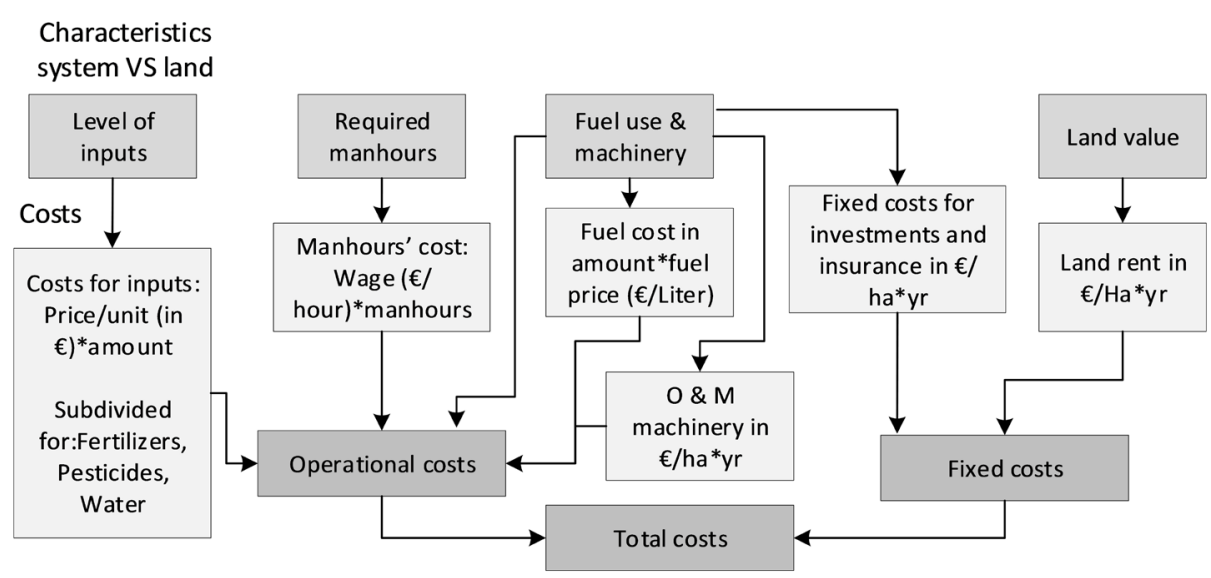

Figure 1. Operational and fixed cost in biomass utilization (Van Dama, Faaija, Lewandowskia, \& Fischerb, 2007).

independent from production level in the short run and the operational costs which are considered to be dependent in short term. Land rental and insurance are incorporated in the fixed costs. On the other hand, consumable goods i.e. fertilizers, pesticides, water consumption and machinery fuels are included in operational costs.

In order to estimate the production cost of various biomass exploitation routes, it is essential, the projected energy prices and $\mathrm{CO}_{2}$ emissions cost to be clearly defined in the reference period. A second step is the energy prices correlation by using a Monte Carlo approach, to calculate the cost of each production path (McLaughlin, Samson, Bransby, \& Wiselogel, 1996).

Corn-stover production does not bring alterations of the preexisting land use. Corn stover exploitation has a relatively minor impact on corn production. Corn stover left overs on the field are assimilated into the top soil in a subsequent planting cycle. Corn stover collecting therefore, increases the depletion of soil nutrients, which necessitates the addition of extra nutrients to boost the fertility. Nutrient enrichment is considered as a part of the production cost and Corn-stover production cost includes merely the cost of harvesting stover since the crop planting and growing phases are attributed to the corn grain cost, given that is consistent, land properties with corn cultivation would be used to produce Stover (Van Dama, Faaija, Lewandowskia, \& Fischerb, 2007). Due to the fact that there's great concern about top soil erosion and moisture problems, a considerable amount of stover still remains on the field after harvesting. Costs per ton include the cost of nutrient replacement and strongly depends on the amount of stover to be collected. The range of areas cultivated and stover quantity for picking determine the type of equipment to be employed. The lowest-yield land employs combine spreader to move the stover into windrows, thereafter are formed into round bales by means of a tractor (LaTourrette, Ortiz, Hlavka, Burger, \& Cecchine, 2011).

An example for harvesting more than 1.2 tons but less than 1.5 tons per acre, is given below where an additional tractor attachment in needed, a front end 
wheel rake, when making windrows (LaTourrette, Ortiz, Hlavka, Burger, \& Cecchine, 2011).

Supposing that the yield is greater than 1.5 tons/acre then,

$$
\begin{aligned}
& \text { Cost }_{\text {stover }>1.5 \text { tons/acre }}(y) \\
& =50.65 *\left(\frac{y \text { tons }}{\text { acre }} * \frac{2.47 \text { acres }}{1 \text { hectare }} * \frac{0.907 \mathrm{Mg}}{1 \text { ton }}\right)^{-0.41} * \frac{149}{98} * \frac{0.907 \mathrm{Mg}}{1 \text { ton }}
\end{aligned}
$$

Supposing that the yield is less than 1.2 tons/acre then,

$$
\begin{aligned}
& \text { Cost }_{\text {stover }<1.2 \text { tons/acre }}(y) \\
& =51.72 *\left(\frac{y \text { tons }}{\text { acre }} * \frac{2.47 \text { acres }}{1 \text { hectare }} * \frac{0.907 \mathrm{Mg}}{1 \text { ton }}\right)^{-0.41} * \frac{149}{98} * \frac{0.907 \mathrm{Mg}}{1 \text { ton }}
\end{aligned}
$$

Considering the yield between 1.2 and 1.5 tons/acre,

$$
\begin{aligned}
& \text { Cost }_{1.2 \text { tons/acre }<\text { stover }<1.5 \text { tons/acre }}(y) \\
& =48.01 *\left(\frac{y \text { tons }}{\text { acre }} * \frac{2.47 \text { acres }}{1 \text { hectare }} * \frac{0.907 \mathrm{Mg}}{1 \text { ton }}\right)^{-0.41} * \frac{149}{98} * \frac{0.907 \mathrm{Mg}}{1 \text { ton }}
\end{aligned}
$$

The impact of sustainability criteria on the cost supply curve of energy crop production and the potential of biomass production is analyzed following the general procedure in the following Figure 2 (LaTourrette, Ortiz, Hlavka, Burger, \& Cecchine, 2011).

\subsection{Transportation and Storage Cost}

Transportation, baled switchgrass storage and corn stover treatment is based on custom rates for agricultural services and recent experience as concerns switchgrass storage. The model looks up the highway distance between the county of production and the county in which the powerplant is located. In all circumstances, normalized transportation cost is estimated, either as per-ton or as per-energy content based on the average mass of the bale (LaTourrette, Ortiz, Hlavka, Burger, \& Cecchine, 2011).

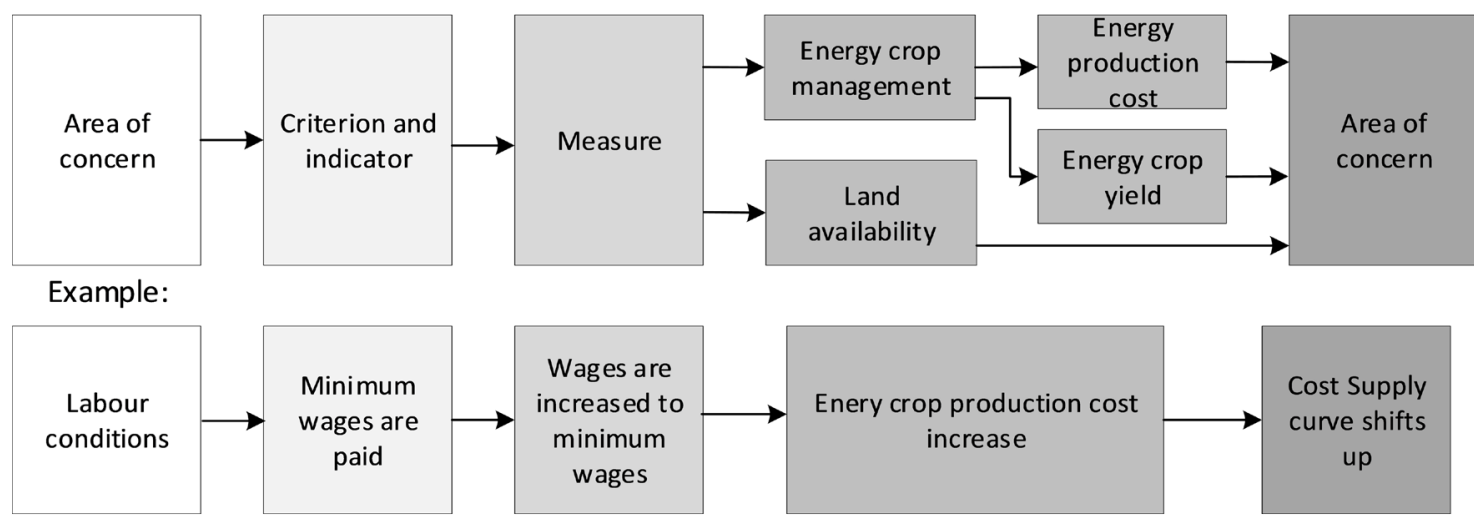

Figure 2. Procedure analysis diagram of biomass production (LaTourrette, Ortiz, Hlavka, Burger, \& Cecchine, 2011). 
Should it be assumed that biomass is stored prior to final utilization, storage cost comprised overall storage barn building cost, (incl. operational cost) as well as bales' loading/unloading cost from the flatbed trailer. Loading and unloading cost is derived from custom rate surveys and standard planning factors for agricultural equipment (LaTourrette, Ortiz, Hlavka, Burger, \& Cecchine, 2011). Biomass transportation from the harvesting spot to a storage facility (season long before the final delivery as an energy source), it is possible to be estimated the cost per ton (or cost per GJ) by using certain estimation parameters. Loading and unloading operation is always included in the overall cost. Transportation and storage cost as per ton delivered basis are presented in the following calculations (LaTourrette, Ortiz, Hlavka, Burger, \& Cecchine, 2011):

$$
\begin{aligned}
& \text { Cost }_{\text {transportation }}(d, m) \\
& =\frac{\frac{\$ 4}{\text { loaded mile }}}{\frac{42 \mathrm{bales}}{\text { load }}\left(\frac{m \text { tons }}{\text { bale }}\right)_{\text {crop }}} d+\frac{2 *(0.5 \mathrm{hr} \text { load }+0.3 \mathrm{hr} \text { unload })}{\frac{42 \text { bales }}{\text { load }}\left(\frac{m \text { tons }}{\text { bale }}\right)_{\text {crop }}} \\
& *\left(\frac{\$ 51}{\mathrm{hr}} \text { loader }+\frac{\$ 69}{\mathrm{hr}} \text { truck } \& \text { trailer }+2 * 1.15 * \frac{\$ 12.50}{\mathrm{hr}}\right. \text { labor } \\
& \left.+60 \mathrm{hp} * \frac{0.044 \mathrm{gal}}{\mathrm{hp} \mathrm{hr}} * 1.15 * \frac{\$ 2.50}{\mathrm{gal}}\right) \\
& +\frac{\frac{\$ 9.00}{\mathrm{ft}^{2}} * 25.000 \mathrm{ft}^{2} * \frac{0.12}{\mathrm{yr}}+2 \mathrm{acres} * \frac{\$ 80}{\mathrm{acre}}}{7.500 \frac{\mathrm{bales}}{\mathrm{yr}}\left(m \frac{\text { tons }}{\text { bale }}\right)_{\text {crop }}}
\end{aligned}
$$

$m$ : the mass of a bale in tons;

$d$ : the distance to be covered.

Storage might affect biomass physicochemical properties. Switchgrass prolonged storage (for several months) allows silica in the switchgrass to dissipate, reducing its potential quality if burned or gasified (Sharif, Nasrulhaq, Majid, Chandran, \& Zuliana, 2007). Baled biomass might undergo biological degradation during long storage. Biomass loss due to switchgrass varies depending on the storage practices. Research on storage methods has provided certain data on biomass loss rates (McLaughlin, Samson, Bransby, \& Wiselogel, 1996).

Outdoor bales' storage on a crushed-rock substrate for 8.5 months might incur losses from 2 up to 4 percent. Switchgrass storage as twine-wrapped bales on sod for 8.5 months might incur losses up to 15 percent. When initial bale moisture and wrapping are variable (13 to 22 percent moisture for net or twine wrapping, respectively), storage for 12 months might incur losses between 5 and 11 percent. No data are available for losses from indoor storage, however according to experts' estimation losses are minimal (Sharif, Nasrulhaq, Majid, Chandran, \& Zuliana, 2007).

Summarizing, the main cost reduction leverage is mostly harvesting, transportation, and residues' loading according to VL Swedish Environmental Re- 
search Institute. Altogether account for around 50 percent of feedstock cost. In each of the processing steps, cost can be reduced by 20 percent through improved baling practices (i.e. larger and denser bales), achieved by using specialized field pressing equipment that increases bale density by 30 percent. Larger and denser bales increase the amount of energy in each loading or transport operation, reducing the operational cost per feed-in unit. In addition, storage cost (some 25 percent of the total cost) can be reduced by up to 90 percent if bales are stored outdoors rather than indoors, and appropriately protected (by plastic tunnels, for example). The capital cost of storage barns erection and maintenance is a large part of the current storage cost.

\subsection{Environmental Impact of Biomass Utilization for Energy Production}

Large-scale biomass cultivation for heat and power production might incur indirect land-use change. Land-use alterations are the result of older land activities to be displaced in favor of biomass feedstock production. Land use changes might cause even severe negative changes such as deforestation. For instance, it's not a rare practice a significant share of the harvested woody biomass used up to now by, to be diverted to the bioenergy sector. Since the demand of forest industry remains high, woody biomass should be sought to other cultivated parts of the world, leading to undesirable negative impact on biodiversity and carbon stocks. The carbon impact of indirect land use change is difficult to be monitored. At the present, there is no consensus in the scientific community as to how the impact should be properly measured through indicators.

There are three main environmental concerns associated with the feedstock biomass production: biodiversity, soil quality, and water habitats.

- Biodiversity can be affected by the conversion of natural habitats-transforming a natural forest to a plantation monoculture, for example-and degradation-by removing deadwood. The former poses the bigger environmental threat, since it can reduce both the number of plants and animal species.

- Soil quality can deteriorate through acidification, land erosion, the release of chemicals, or a change in the balance of nutrients. Fertilizers overuse may also pollute groundwater table due to nitrates high concentration.

- Water habitats can be degraded by nutrients topsoil infiltration, inorganic soil particles precipitation, acidic compounds, other chemicals i.e. pesticides, herbicides and by damage to the shorelines that protect them.

In a nutshell, when bioenergy production is the case, forest and agricultural management practices need further development for biodiversity protection with the due respect to local or regional individualities in terms of land utilization. Feedstock production derived from agricultural residues entails minor environmental risk given that it is by definition by-product. On the other hand, traditional forest production and energy crop or forest plantations can cause greater damage to the ecosystem under poor management. 


\subsection{Good Practices of Biomass Energy}

Countries such as Austria, Brazil, Denmark, Finland, Sweden, India, the USA and the UK are actively encouraging the use of biomass for energy production, and promote systematically all necessary "know how" in biomass management and innovative technologies to meet all new environmental requirements for greener production (Hall, Rosillo-Calle, Williams, \& Woods, 1993).

In the USA, in the UK and in Sweden, all stakeholders develop, even at the early stages, good practice guidelines for the biomass energy use. These guidelines recognize the vital importance of renewable energy, for the current energy share which is prerequisite to confront climate change issues and the profound impact to the modern society and to stop turning a blind eye to the obsolete fossil fuel for energy production. Guidelines are all concentrating on short rotation coppice, perennial grasses and their residues.

A key message of these guidelines (Hall, Rosillo-Calle, Williams, \& Woods, 1993) is that both site and crop selection should be made carefully, and the crop should be managed carefully. Land should be primarily agricultural and energy crops should never displace prior land uses of high ecological value. Deep consideration needs to be given to the landscape, visibility, soil type, water use, transportation access, nature conservation, archaeological interest, pests and diseases that might occur and the public access.

The guidelines also stress the importance of local people consultation during the planning stage and the community involvement in the developing stages. Issues such as landscape changes, traffic movement increment, or new employment opportunities in rural areas may prove to be very significant to local people. Moreover, careful site selection could be environmentally beneficial. Energy crops are also environmentally preferable compared to intensive agriculture, since fertilizers to be used are lower and the soil undergoes less microbial disturbance and compaction.

As regards wildlife, energy crops cultivation is considered to be in some cases similar to agricultural monocultures, though different species will be favored. A good cultivation site selection, field layout, species mixing and sensitive management practices, result in positive overall outcome, quite beneficial to birds, wild plants, soil microorganisms and other species.

Biomass acceptability for energy production is getting stronger and stronger since is it well established that it can be environmentally friendly so as to be accepted as an important fuel of the future and a main weapon to abate greenhouse gases in the near future at least in energy production sector (Hall, Rosillo-Calle, Williams, \& Woods, 1993).

A decade before, several scenarios were published by the European Commission concerning the future targets in Europe the forthcoming years regarding biomass penetration in Energy production. As given in the below Figure, annual biomass heat and power consumption was predicted to grow by a full 850 -Terawatt hours (TWh) by 2020 to a total of 1650 TWh, i.e., a doubling of 2010's level and 
a growth equal to the combined growth of all other renewable energy sources (Faaij, Wagener, Junginger, van Weereld, Schouwenberg, Kwant et al., 2006). As a reference line, 850 TWh of energy production correspond to roughly half of 2010's energy consumption derived from coal and lignite in the EU countries. In terms of primary energy supply, the consumption is roughly equal to the annual harvest of round wood in the EU (Faaij, Wagener, Junginger, van Weereld, Schouwenberg, Kwant et al., 2006).

\subsection{Economic Evaluation of Biomass Energy}

The biomass systems adopted must demonstrate clear environmental and social benefits. These benefits are not inherent to biomass energy, but depend on site-and fuel cycle-specific factors. Life-cycle analysis and evaluation of external costs are important means for assessing the social and environmental pros and cons of bioenergy systems (Hall, Rosillo-Calle, Williams, \& Woods, 1993).

Powerplants that utilize biomass as feedstock introduce new job vacancies. Although job vacancies do not necessarily mean social benefits, still positive externalities arise to reduce unemployment indices when certain limits are surpassed. New job vacancies are considered a social benefit and as such biomass projects are really helpful towards this direction since they favor direct and indirect new job vacancies (Faaij, Wagener, Junginger, van Weereld, Schouwenberg, Kwant et al., 2006). Powerplant installation, substructures, operation and energy corps cultivation are considered to be the direct cost. On the other hand, jobs related to the biomass energy production facilities, goods \& services provision, and in general a supply network to sustain unit's operation unbroken. The indirect part includes the investment needed for the project completion, a prospect that stimulates the local economy and increase employees' number.

Health problems are strongly associated with the atmospheric emissions produced during biomass power generation (Faaij, Wagener, Junginger, van Weereld, Schouwenberg, Kwant et al., 2006). The emissions are considered to be roughly $640 \mathrm{gNO}_{\mathrm{x}} / \mathrm{MWh}$, and $160 \mathrm{~g} / \mathrm{MWh}$ particulates (PMs). $\mathrm{SO}_{2}$ emissions are rather negligible at this stage. The emissions generated for the rest of the stages of the biomass fuel cycle have been estimated. For instance, emissions produced during biofuel transport. However, there were found to be negligible in comparison with power generation emissions, as consolidated by the studies.

The biggest advantage of biomass systems is that they are $\mathrm{CO}_{2}$-neutral, or even with negative sign. Carbon emissions of the overall biomass fuel cycle have been estimated. Biomass cultivation, transport and power generation are activities with a net release of carbon to the atmosphere (Macedo, 1998). Biomass releases net GHG emissions as a result of biomass production, including vehicle emissions, fertilizer's production and denitrification into nitrous oxide (a very powerful greenhouse gas), and soil carbon retention or depletion dependent on crop and land type (Faaij, Wagener, Junginger, van Weereld, Schouwenberg, 
Kwant et al., 2006). Nonetheless, biomass-based energy production is more expensive per MWh electricity produced than fossil fuel alternatives at today's carbon dioxide emission prices. This is one of the key reasons why biomass growth is relatively slow compared to other counterparts.

The figure below presents the cost competitiveness of biomass energy versus all competing technologies with a low carbon dioxide price of 30 to 50 EUR per ton and a projection to 2020 (LaTourrette, Ortiz, Hlavka, Burger, \& Cecchine, 2011).

The biomass systems adopted must demonstrate clear environmental and social benefits. These benefits are not inherent to biomass energy, but depend on site-and fuel cycle-specific factors. Life-cycle analysis and evaluation of external costs are important means for assessing the social and environmental pros and cons of bioenergy systems (Hall, Rosillo-Calle, Williams, \& Woods, 1993).

Powerplants that utilize biomass as feedstock introduce new job vacancies. Although job vacancies do not necessarily mean social benefits, still positive externalities arise to reduce unemployment indices when certain limits are surpassed. New job vacancies are considered a social benefit and as such biomass projects are really helpful towards this direction since they favor direct and indirect new job vacancies (Faaij, Wagener, Junginger, van Weereld, Schouwenberg, Kwant et al., 2006). Powerplant installation, substructures, operation and energy corps cultivation is considered to be the direct cost. On the other hand, jobs related to the biomass energy production facilities, goods \& services provision, and in general a supply network to sustain unit's operation unbroken. The indirect part includes the investment needed for the project completion, a prospect that stimulates the local economy and increase employees' number.

Health problems are strongly associated with the atmospheric emissions produced during biomass power generation (Faaij, Wagener, Junginger, van Weereld, Schouwenberg, Kwant et al., 2006). The emissions are considered to be roughly $640 \mathrm{gNO}_{\mathrm{x}} / \mathrm{MWh}$, and $160 \mathrm{~g} / \mathrm{MWh}$ particulates (PMs). $\mathrm{SO}_{2}$ emissions are rather negligible at this stage. The emissions generated for the rest of the stages of the biomass fuel cycle have been estimated. For instance, emissions produced during biofuel transport. However, there were found to be negligible in comparison with power generation emissions, as consolidated by the studies.

The biggest advantage of biomass systems is that they are $\mathrm{CO}_{2}$-neutral, or even with negative sign. Carbon emissions of the overall biomass fuel cycle have been estimated. Biomass cultivation, transport and power generation are activities with a net release of carbon to the atmosphere (Hall, Rosillo-Calle, Williams, \& Woods, 1993). Biomass releases net GHG emissions as a result of biomass production, including vehicle emissions, fertilizer's production and denitrification into nitrous oxide (a very powerful greenhouse gas), and soil carbon retention or depletion dependent on crop and land type (LaTourrette, Ortiz, Hlavka, Burger, \& Cecchine, 2011). Nonetheless, biomass-based energy production is 
more expensive per MWh electricity produced than fossil fuel alternatives at today's carbon dioxide emission prices. This is one of the key reasons why biomass growth is relatively slow compared to other counterparts. The figure below presents the cost competitiveness of biomass energy versus all competing technologies with a low carbon dioxide price of 30 to 50 EUR per ton and a projection to 2020 (Faaij, Wagener, Junginger, van Weereld, Schouwenberg, Kwant et al., 2006).

Should the above figure set for further interpretation the reasonable outcome might be the fact that biomass could be cost competitive without any specific incentives in some 10 or 15 years from now on. Such a prospect will diminish the political risk and encourage policy makers to announce only transitionary incentives which are much easier to apply.

\subsection{Strategic Planning of Biomass Energy}

The market for biomass is developing rapidly and becoming more outward looking (Heinimö, 2008). For example, specific well-consolidated areas as major biofuels providers are undergoing quick expansion and even more biomass is being importing from remote countries (even from other continents). It has been observed that certain areas have a biomass potential that exceeds the local consumption needs. At the same time in some other areas' biofuel demand surpasses the local production potential (An \& Searcy, 2012). Consequently, some areas are becoming bioenergy suppliers to regions that have fewer biomass resources.

A vivid and well-functioning international biomass market will be the regulator of the key factors applied, combining the production potential and the growing demand for biomass. Politicians, energy decisions makers, market strategy analysts, researchers, stakeholders start prioritizing the future development of the biomass market (An \& Searcy, 2012).

Systematic and proven methods are available for foreseeing alternative development paths and increasing capabilities to confront unexpected, diverted development (An \& Searcy, 2012). The methods of group assessment and group decision support system provide tools for scenario processing, incorporating experts' valuable knowledge.

Various instances of successful application of the decision support system in scenario research can be found; that is in the multi-period scenario development (Faaij, Wagener, Junginger, van Weereld, Schouwenberg, Kwant et al., 2006), for assisting decision makers in the promotion of renewable energy sources (Van Dama, Faaija, Lewandowskia, \& Fischerb, 2007) and in the strategic innovation processes (Faaij, Wagener, Junginger, van Weereld, Schouwenberg, Kwant et al., 2006).

Scenario planning is one of the most frequently applied methods for evaluating future development routes. It is a structured strategic planning method that is used to make flexible long-term plans. It is applied to policy planning; in or- 
ganizational development; and, more generally, when strategies are needed for testing against uncertain future development (An \& Searcy, 2012).

General Electric and Shell companies are well-known examples of large firms that have been among the pioneering adopters of scenario approaches as strategic management tools. In strategic planning, scenarios are argued to be especially efficient when uncertainties related to business and the future play a significant role in the industry. Basically, the process can be simplified into four main phases presented as follow:

1) Structuring the scenario process. This includes background analysis of the scenario context and delimitation of the focus.

2) Exploring the scenario context. This includes determining the main stakeholders, driving forces and the key environmental uncertainties that are changing the operational environment. Furthermore, the significance of the main driving forces is explored.

3) Development of scenarios. This phase provides alternative future scenarios related to the issue being considered.

4) Implementation of the scenarios.

Scenario planning is a method for learning about the future by understanding the nature and impact of the most uncertain and important driving forces which affect the near future. Commonly, scenario planning yields 3 - 5 diverging scenarios descriptive of a future situation. It is really helpful to policy-makers to anticipate hidden weaknesses and inflexibilities in organizations and methods. Thus, certain weaknesses can be avoided in advance. Scenario planning is getting even more important in cases that the research issue is undergoing alterations and there's high uncertainty of the research question is high and there are multiple resolutions to the issue (Faaij, Wagener, Junginger, van Weereld, Schouwenberg, Kwant et al., 2006). Stakeholders then are able to formulate strategies that account for environmental changes and make use of future opportunities with an acceptable risk level. Scenarios also serve as a platform for the evaluation of new business ideas and policies, assessing their market potential and possible impacts, though, e.g. posing "what if" questions.

The scenario process could be approached as a heuristic process (An \& Searcy, 2012) with intuitive and systematic elements or even as a "participative" stage process (Faaij, Wagener, Junginger, van Weereld, Schouwenberg, Kwant et al., 2006) where in business decision analysis, decision and policy-makers play a significant role apart from the group of technical experts to be responsible for design and development of scenarios. Schematic paradigms of such scenarios are given in Figure 3 below (An \& Searcy, 2012).

A SWOT analysis is also a strategic planning tool used to evaluate the Strengths, Weaknesses, Opportunities, and Threats. The objective of SWOT analysis is to demonstrate a vital, functional and sustainable biomass in order to replace fossil fuels, for energy purposes. A general SWOT matrix is shown, below Table 1. 


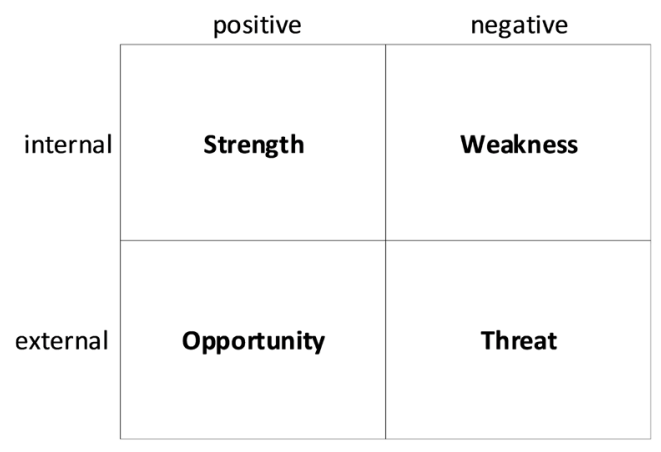

Policy and environment "The EU rolls"

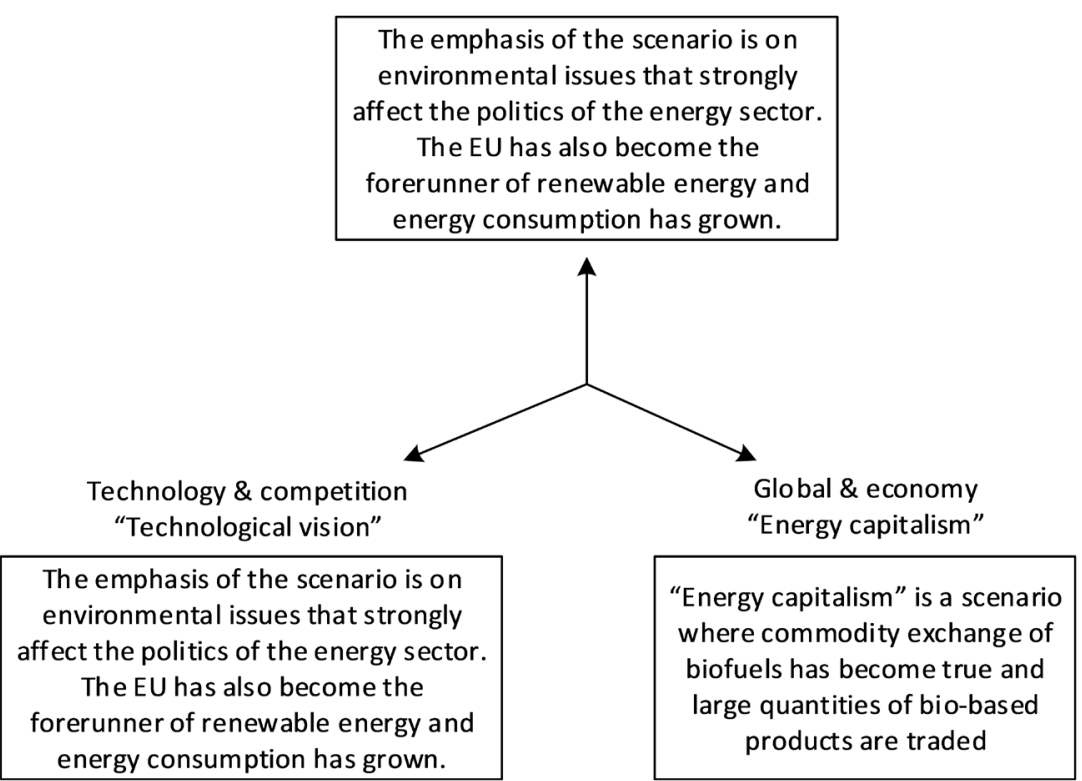

Figure 3. Schematic paradigm of a heuristic process for the evaluation of new business ideas and policies.

Table 1. A SWOT analysis approach concerning biomass energy field.

\begin{tabular}{ll}
\hline \multicolumn{1}{c}{ Strengths } & \multicolumn{1}{c}{ Weaknesses } \\
\hline $\begin{array}{l}\text { Flexible in land choice } \\
\text { Large amount of agricultural and industrial biomass }\end{array}$ & Lack of proper quality biomass in certain regions for energy production \\
$\begin{array}{l}\text { High value of natural heritage that favors clean energies } \\
\text { development }\end{array}$ & Renewable energy business sector is weak \\
High interest in energy management discipline in & Absence of lack of sufficient financial mechanisms to endeavor RES penetration \\
Universities & Low quality of electricity on determined areas \\
$\begin{array}{l}\text { Improved cultivation practices that increase biomass } \\
\text { productivity }\end{array}$ & Insufficient infrastructure for biomass distribution \\
Mature technologies in Energy production derived from & Low sensitiveness to energy saving \\
agro-byproducts. & Controllability system is low (control by private parties) \\
& Translation "do more good" is limited \\
& $\begin{array}{l}\text { Expensive (administration is expensive for companies and therefore } \\
\text { difficult to apply for small holders) }\end{array}$ \\
& None or low individual awareness for Renewable Energy utilization \\
& Dependency on electricity network \\
\hline
\end{tabular}


Continued

\begin{tabular}{ll}
\hline \multicolumn{1}{c}{ Opportunities } & \multicolumn{1}{c}{ Threats } \\
\hline $\begin{array}{ll}\text { Investment motives, on national scale, to encourage } \\
\text { biomass energy projects, (subsidies to enhance renewable }\end{array}$ & $\begin{array}{l}\text { Progressive environmental deterioration } \\
\text { Excessive dependency on fossil fuels }\end{array}$ \\
$\begin{array}{l}\text { Existence of applicable funds to invest in energy system } \\
\text { development }\end{array}$ & Risk of energy resources price increase \\
$\begin{array}{ll}\text { High land availability for biomass energy development } \\
\text { Proper local climate to enforce biomass production }\end{array}$ & \\
\end{tabular}

\section{Discussion}

Biomass derived energy production is fundamental to secure the global climate balance and economic growth indices. Biomass was in the past an important source of energy and is expected to remain as such. However, it is expected a huge expansion in use as a counterbalance to the environmental confronted problems caused by the extended use of conventional fossil fuel and affect most notably the climate change. Bioenergy has been proposed as the main pillar in energy consumption apart from other forms of renewable energy (Hall, Rosillo-Calle, Williams, \& Woods, 1993).

Biomass, as fossil fuels, releases carbon dioxide when it is burned. Whereas emissions from fossil fuels combustion are net additions of carbon dioxide to the atmosphere, carbon dioxide released from biomass utilization becomes part of a natural cycle that entails no net additions.

Both biochemical processing and production research will be vitally important to advance and to proceed to the adoption of biofuels and profit margins improvement. The major barriers to reach in short-term adaptation of biomass as a basic energy pillar are mainly economic. However, renewable energy crops are now very competitive against fossil fuels and gas in terms of combined energy, ecological and financial standpoint. Policy decisionmakers recognize and reward the intrinsic values of the biomass utilization network and promote gradually energy crops into the energy strategy of each country. A creative and resourceful industry will improve the energy conversion technology and cost margins of the exploitation chain. There inherent benefits investing in a biomass system supply the added value to society at a local, regional, and global scale (McLaughlin, Samson, Bransby, \& Wiselogel, 1996).

In the table below given, are summarized all types of barriers and the needed actions for expanding biomass for heat and power (An \& Searcy, 2012).

The role of biomass in the future global energy supply could be very substantial if real action is taken to prevent global climate change, and the modern biomass industry is developed in a sensitive and responsible manner (Hall, Rosillo-Calle, Williams, \& Woods, 1993). The benefits of sustainably produced biomass energy in future energy scenarios have recently been acknowledged in many scientific studies. 
A study conducted by Shell International Petroleum Company (1996), carried out a scenario analysis in which is predicted that the major new sources of energy after 2020 were going to be the renewable energy since it was expected that had already progressed enough up to the point to consider it as mature and directly competitive against fossil fuels. According to this old study, after 2020, in this business-as-usual scenario, the renewable energy forms i.e. biomass, wind, solar and geothermal were expected to be the major new energy suppliers

Experts emphasize the huge role of biomass which is expected to undertake in the near future a great share of the global energy supply (Hall, Rosillo-Calle, Williams, \& Woods, 1993). Biomass fuels can substitute just as good for fossil fuels in the existing energy supply infrastructure. Intermittent renewables such as wind and solar energy are even more challenging to the ways we distribute and consume energy.

Biomass sources potential is high since there's sufficient land dedicated to food production and thus other land squares with lower growth yield are available for energy plants cultivation which continue to rise energy biomass production.

Energy demand in the developing countries is rising rapidly due to population increase, urbanization and rising living standards. While some fuel switching occurs in this ongoing process, the total biomass demand demonstrates an upward trend.

In low- and middle-income countries, in urban areas, all types of energy gas i.e. LPG, Natural Gas, and Biogas have already overtaken unprocessed biomass as the dominant fuel since 2010. On the contrary, in rural areas, unprocessed biomass remains dominant, though declining. It is estimated that 2.3 billion people until 2030 will continue to rely on traditional uses of biomass along with kerosene, or coal as the main energy sources primarily for cooking fuel (Tracking SDF 7, The Energy Progress Report., 2020).

Though the share of renewables in the heating sector reached 23.5 percent of total final heat consumption in 2017, still traditional uses of biomass remained relatively unchanged in 2017 , accounting for merely $14 \%$ of global heat consumption. In the transport sector, renewables' share remained at 3.3\% (2017), consumed mainly as liquid biofuels, crop-based ethanol and biodiesel. Renewable electricity in the transport sector in the same year was approached a $0.3 \%$ of the total energy consumption worldwide (Tracking SDF 7, The Energy Progress Report., 2020).

The World Bank Industry and Energy Department, in 1996 concluded that ... energy policies need to concern about the supply and use of biofuels as much as about conventional fossil fuels ... and should support the means to utilize biofuels more efficiently and sustainably... This was an important change of perspective for the World Bank's thinker tank, though there has been a misconception that biofuels were necessarily not "modern".

Governments should draw attention to take all measurements to achieve a positive cost/benefit ratio and significantly alleviate the investment bottleneck that currently constrains the growth of biomass-based industries. It is obvious 
that a lot of benefits can be emerged involving both the environment and the security of energy supply, many of which it is not possible up to now, to be quantified. An important challenge in developing a national energy supply strategy is a definition of policies that could most effectively facilitate translation of ecological and economic values of renewable energy crops into increased production and utilization of renewable fuels (McLaughlin, Samson, Bransby, \& Wiselogel, 1996).

\section{Conclusion}

In the present work, a holistic, multi-factorial approach of biomass exploitation in many important aspects of our economies and its contribution in energy contribution were attempted to be analyzed.

Storage might affect biomass physicochemical properties. Decision support system in scenario research could be assisting to decision makers as regards the promotion of renewable energy sources and the strategic innovation processes. There are significant cost improvement opportunities in all steps of the biomass energy production chain. Biomass acceptability for energy production is getting stronger and stronger since it is well established that it can be environmentally friendly so as to be accepted as an important fuel of the future.

Certain uses of biomass are considered to be renewable, since biomass contributes in many ways to economic and environmental sustainability. Numerous countries were committed to achieve certain renewable targets goals regarding renewable energy forms' penetration in the overall energy mixture, including biomass, wind, solar and geothermal fields. Nonetheless, there are quite a few barriers (guidelines) associated with legislation modernization and biomass use expansion that European governments should take into consideration.

\section{Conflicts of Interest}

The authors declare no conflicts of interest regarding the publication of this paper.

\section{References}

An, H., \& Searcy, S. W. (2012). Searcy Economic and Energy Evaluation of a Logistics System Based on Biomass Modules. Biomass and Bioenergy, 46, 190-202. https://doi.org/10.1016/j.biombioe.2012.09.002

Faaij, A., Wagener, M., Junginger, M., van Weereld, A., Schouwenberg, P., Kwant, K. et al. (2006) Opportunities and Barriers for Sustainable International Bio-Energy Trade: Towards a Strategic Advice of IEA Task 40. In 14th European Biomass Conference, 17-21 October, Paris, France.

Greene, D. L., \& Tishchishyna, N. I. (2000). Costs of Oil Dependence: ORNL/TM-2000/152. Oak Ridge, TN: Oak Ridge National Laboratory.

Hall, D. O., \& Scrase, J. I. (1998). Will Biomass Be the Environmentally Friendly Fuel of the Future? Biomass and Bioenergy, 15, 357-367. https://doi.org/10.1016/S0961-9534(98)00030-0 
Hall, D. O., Rosillo-Calle, F., Williams, R. H., \& Woods, J. (1993). Biomass for Energy: Supply Prospects. In B. J. Johansson, H. Kelly, A. K. N. Reddy, \& R. H. Williams (Eds.), Renewable Energy: Sources for Fuels and Electricity (pp. 583-652). Washington DC: Island Press.

Heinimö, J. (2008). Methodological Aspects on International Biofuels Trade: International Streams and Trade of Solid and Liquid Biofuels in Finland. Biomass and Bioenergy, 32, 702-716. https://doi.org/10.1016/j.biombioe.2008.01.003

Hubbard, H. (1991). The Real Cost of Energy. Scientific American, 264, 36-42. https://doi.org/10.1038/scientificamerican0491-36

Klass, L. D. (1998). Energy Consumption, Reserves, Depletion, and Environmental Issues. In D. L. Klass (Ed.), Biomass for Renewable Energy, Fuels, and Chemicals (pp. 1-27). New York, NY: Academic Press.

Kulkarni, M. G., \& Dalai, A. K. (2006). Waste Cooking Oil-An Economical Source for Biodiesel: A Review. Industrial \& Engineering Chemistry Research, 45, 2901-2913. https://doi.org/10.1021/ie0510526

LaTourrette, T., Ortiz, D. S, Hlavka, E., Burger, H., \& Cecchine, G. (2011). Supplying Biomass to Power Plants: A Model of the Costs of Utilizing Agricultural Biomass in Cofired Power Plants. Pittsburgh, PA, Morgantown, WV, and Albany, OR: National Energy Technology Laboratory. https://doi.org/10.2172/1515273

Macedo, I. D. C. (1998). Energy from Biomass and Wastes. Biomass \& Bioenergy, 3, 77-80.

McLaughlin, S. B., Samson, R., Bransby, D., \& Wiselogel, A. (1996) Evaluating Physical, Chemical, and Energetic Properties of Perennial Grasses as Biofuels. 7 th National Bioenergy Conference, Nashville, 15-20 September 1996. https://doi.org/10.1016/s0140-6701(98)96595-X

Sharif, A. B. M. H., Nasrulhaq, A. B., Majid, H. A. M., Chandran, S., \& Zuliana, R. (2007). Biodiesel Production from Waste Cooking Oil as Environmental Benefits and Recycling Process. A Review. Asia Biofuel Conference Book, Singapore, 11-13 December 2007.

Sharif, H., Aishah, S., Boyce, A., Chowdhury, P., \& Naqiuddin, M. (2008). Biodiesel Fuel Production from Algae as Renewable Energy A.B.M. American Journal of Biochemistry and Biotechnology, 4, 250-254.

Tracking SDF 7, The Energy Progress Report (2020). International Bank for Reconstruction and Development. Washington DC: The World Bank. https://unstats.un.org/unsd/energystats/pubs/documents/sdg_7_2020.pdf

Turkenburg, W. C. (2000). Renewable Energy Technologies. In J. Goldemberg (Ed.), World Energy Assessment, Preface (pp. 219-272). New York, NY: United Nations Development Programme.

Van Dama, J., Faaija, A. P. C., Lewandowskia, I., \& Fischerb, G. (2007). Biomass Production Potentials in Central and Eastern Europe under Different Scenarios. Biomass and Bioenergy, 31, 345-366. https://doi.org/10.1016/j.biombioe.2006.10.001 